\section{Case Report}

() 2021 Moustapha et al.

Submitted: 28-03-2021

Accepted: $05-05-2021$

License: This work is licensed under

a Creative Commons Attribution 4.0

International License.

DOI: https://doi.org/10.47338/jns.v10.963

\title{
Neonatal oral teratoma: A case report
}

Helle Moustapha, ${ }^{1}$ Oumarou Habou ${ }^{2}{ }^{*}$ Kadre Alio Kadre Ousmane, ${ }^{3}$ Mahamoud Omid Ali Ada, ${ }^{1}$

Inoussa Daouda Bako, ${ }^{4}$ Boubacar Effared, ${ }^{5}$ Ramatou Sabo, ${ }^{1}$ Habibou Abarchi, ${ }^{1}$

1: Department of Pediatric Surgery, Amirou Boubacar Diallo National Hospital of Niamey, Faculty of Health Sciences, Abdou Moumouni University, Niger. 2: Department of Surgery Pediatric Surgery, National Hospital of Zinder, Faculty of Health Sciences, University of Zinder, Niger. 3: Department of Stomatology and Maxillofacial Surgery, General Hospital of Niamey, Faculty of Health Sciences, Abdou Moumouni University, Niger. 4: Department of Radiology, National Hospital of Niamey, Faculty of Health Sciences, Abdou Moumouni University, Niamey, Niger. 5: Laboratory of Pathology, Faculty of Health Sciences, Abdou Moumouni University, Niamey, Niger

Correspondence*: Dr. Habou Oumarou, Professor of Pediatric Surgery, Faculty of Health Sciences, University of Zinder (Niger); BP: 656 Zinder, Niger. E-mail: bhomar70@yahoo.fr

\section{KEYWORDS}

Teratoma,

Oral tumor,

Neonate

\section{ABSTRACT}

Background: Teratomas of the oral cavity are rare and can pose danger to a patient's life in terms of obstruction to the aerodigestive tract. These are the germ cell tumors that arise from all three layers of primordial germ cells.

Case Presentation: A 2-day-old female neonate presented with a mass protruding from the oral cavity since birth with no significant antenatal history. Examination revealed a large (8 $\mathrm{cm})$, firm, and irregular mass protruding from the oral cavity extending up to the inner surface of the upper lip and onto the gums, associated with cleft palate. Complete excision of the mass was done and histopathology confirmed the diagnosis. There were no postoperative complications.

Conclusion: Oral cavity teratoma is a rare tumor with a good prognosis especially in its mature form. Surgical excision with multidisciplinary collaboration is needed in order to avoid any complications.

\section{INTRODUCTION}

Oral teratomas are unusual and potentially fatal by causing the aero-digestive obstruction.[1] Teratomas are germ-cell tumors that derive from the 3 primordial germinal layers. Sacrococcygeal location is frequent (80\%) and only $3 \%$ are facio-cervical in location.[2] The diagnosis can be made in the antenatal period, but in most cases, it is diagnosed during the postnatal period. The etiological diagnosis and management constitute a challenge, particularly in low-income countries. We are presenting a rare case of teratoma in the oral cavity of a two days old neonate. To the author's best knowledge, it is a first case report from Niger.

\section{CASE REPORT}

A 2-day-old female neonate brought to our service for a congenital anomaly of the face noticed at birth. No particular pathological perinatal history was present. She was the third product of non-consanguineous marriage to a 25-year-old mother. It was a full-term pregnancy without any prenatal consultation or obstetric ultrasound; with normal vaginal delivery at home (birth weight of $2.8 \mathrm{~kg}$ ). On general physical examination, there was a large, firm oral mass obstructing the oral cavity (Fig.1A,1B), measuring approximately $8 \mathrm{~cm}$ in the long axis, irregular in appearance, with the presence of a tuft of hair on the outer edges, crossing the midline and extending to the inner surface of the upper lip and onto the gums. The oral examination noted a right transverse cleft (unilateral congenital macrostomia) associated with a velopalatal cleft and the tongue was free. The assessment made by trans-fontanelle ultrasound, echocardiography, and abdominopelvic ultrasound revealed no associated abnormalities. The ageadjusted a-fetoprotein (AFP) value was normal (10200 $\mathrm{ng} / \mathrm{ml})$. The CT scan confirmed the multi-tissue and solid components of the mass (Fig.2). The management was multidisciplinary. Complete surgical excision was performed on day 5 of life with orotracheal intubation. The postoperative recovery was uneventful and the patient was discharged on the 10th day. Histopathology revealed a mature teratoma without any evidence of immature cells (Fig.3A,3B). Velopalatal cleft surgery (and transverse cleft) had been postponed (as well as secondary upper lip 
surgery). Follow-up at 6 months showed a good aesthetic result.

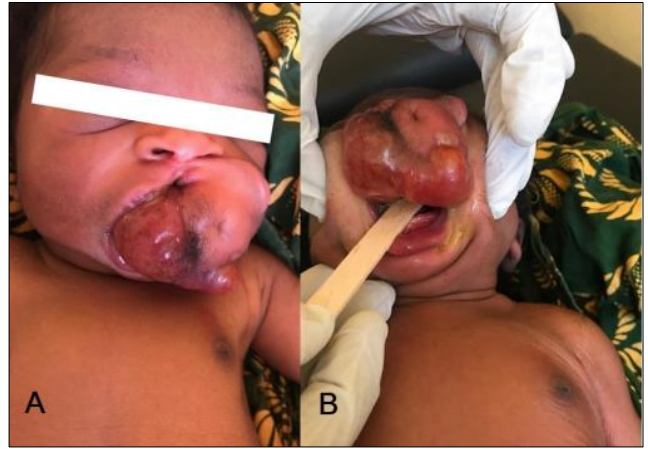

Figure $1(\mathrm{~A}, \mathrm{~B})$ : Mass arising from the oral cavity

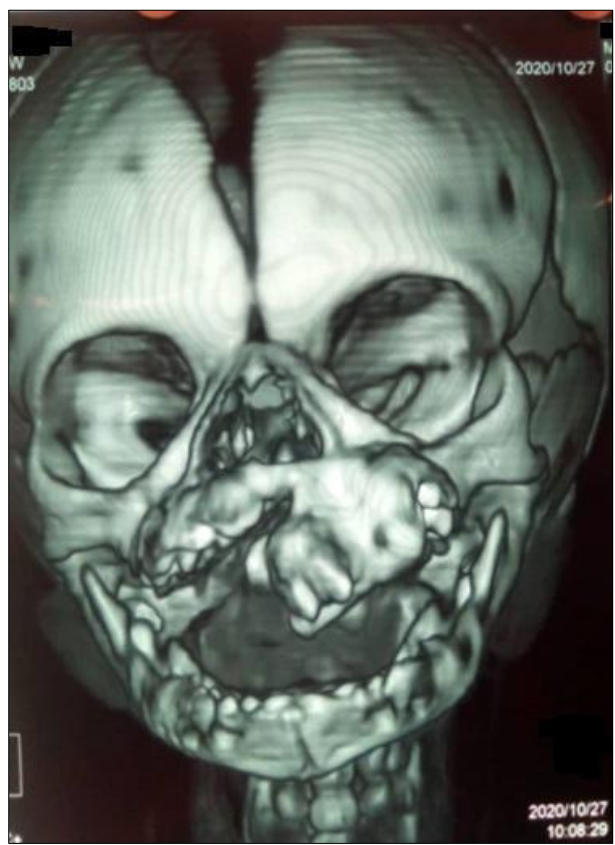

Figure 2: CT scan showing a multi-tissue oral lesion suggestive of a teratoma.

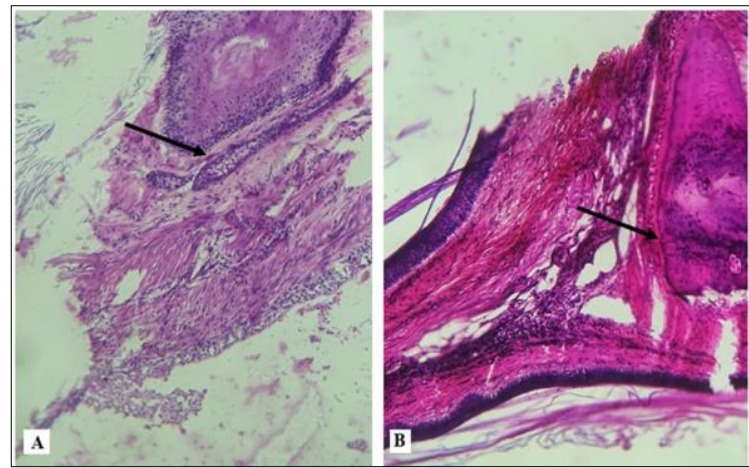

Figure 3: A) A cystic formation with localized mature skin tissue associated with sebaceous glands (arrow) arranged over mature smooth muscle tissue (HE $\times 100)$. B) Another area of the lesion showing mature bone tissue $(\mathrm{HE} \times 200)$.

\section{DISCUSSION}

Congenital teratomas are observed in 1/4000 births with a female predominance.[2] They are rare, can be seen at all ages, and constitute approximately $1.6 \%$ to $6.5 \%$ of all locations.[3,4] The diagnosis can be made on prenatal ultrasound, especially in case of a large tumor. In the postnatal period, the presence of large irregular shaped tumor deforming the oral morphology points towards the diagnosis. The floor of the mouth teratomas are often found in the midline but in $6 \%$ of cases, they are present laterally.[5] They can compress adjacent tissues, mainly the aerodigestive tract, and thus cause neonatal respiratory distress and difficulty in feeding. Hence early diagnosis is important.

Other complications, notably functional and aesthetic, by deformation of the nasolabial structures, can be observed. Thus, these congenital tumors of the oral cavity can be responsible for intraoral and/or orofacial malformations when they develop in the early weeks of embryonic life.[6] CT scan is helpful in the diagnosis and noting the origin and extent of the lesion, and histology helps to identify the type.[4]

Other associated anomalies are also found, especially a cleft palate, the treatment of which is often delayed. The complexity of the associated malformation is therefore variable depending on the time of development of teratoma during the embryological period.[6] In fact, these oral tumors hinder palatal closure either in lingual or nasopharyngeal locations.[5,7] Thus when the tumor develops at the upper labio-gingivoalveolar level, the development of labio-palatal clefts occur secondary to the mechanical obstruction to the closure of palatine shelves by incarceration of the tongue in the midline or right lateral position.

Treatment is essentially surgical based on complete tumor excision. It must be performed early in order to avoid complications. Complete surgical excision is recommended. Macroscopically, benign teratoma is more often heterogeneous and contains several types of mature tissue. Histologically, the teratoma is a true tumor, comprising tissues foreign to the region which shelters it, resembling those which succeed one another during embryonic development from the 3 germinal layers. [8] The risk of malignancy is seen in teratomas of the gonads (especially ovaries) with an incidence related to the age of presentation but also in case of incomplete excision. On the other hand, for teratomas of the floor of the mouth, the risk of malignant transformation is exceptional.[9,10]. Multidisciplinary collaboration including different specialties (pediatrician, pediatric surgeons, anesthesiologist, pathologist, radiologist, etc.) is necessary in order to improve the prognosis.

\section{Acknowledgements: $\mathrm{Ni}$}

Conflict of Interest: Authors have no conflict of interest.

\section{Source of Support: Nil}

Consent to Publication: Author(s) declared taking informed written consent for the publication of clinical photographs/material (if any 
used), from the legal guardian of the patient with an understanding that every effort will be made to conceal the identity of the patient, however it cannot be guaranteed.

\section{REFERENCES}

1. Samiul Hasan, Nadia Afroz, Jiaul Reza. Tongue shaped oropharyngeal teratoma with cleft palate in a neonate: A case report. J Neonatal Surg. 2021; 10: 13.

2. Belaloui MO, Boughaba N, Atrih Z, Boussouf MS. Congenital cervical teratoma. Lettre d'ORL et Chirurgie Cervico-Faciale. 2012; 328:30-1. [Article in French]

3. Lakhoo K. Neonatal teratomas. Early Hum Dev. 2010; 86: 643-7.

4. Moumine M, Choumi F, Sabani H, El Khatib MK, Naasih M. A teratoma of the floor of the mouth, Chirurgie Buccale. 2014; 20:289-90. [Article in French]

5. Kadre A, Moustapha H, Boubacar E, Ali Ada MO, Gaoh HD, Ille S. Congenital tumors of the oral cavity: About 2 cases. Jaccr Africa. 2018; 2:54-8. [Article in French]

6. Lavocat R, Szwebel JD, Mitrofanoff M. Inferior cervicomaxillary median cleft: case report, ethiopathogenic and therapeutic focus. Ann Chir
Author Contributions: Author(s) declared to fulfil authorship criteria as devised by ICMJE and approved the final version.

Plastique Esthétique. 2011; 56: 334-8. [Article in French]

7. Bergé SJ, von Lindern JJ, Appel T, Braumann B, Niederhagen B. Diagnosis and management of cervical teratomas. Br J Oral Maxillofac Surg. 2004; 42:41-5.

8. Boko E, Amaglo K, Kpemissi E. A bulky dermoid cyst of the floor of the mouth. Eur Ann Otorhinolaryngol Head Neck Dis. 2014; 131:131-4.

9. Benouaiche L, Couly G, Michel B, Devauchelle B. Diagnosis and management of congenital cervicofacial teratomas: about 4 cases, review of the literature and update. Ann Chir Plast Esthet. 2007; 52:114-23. [Article in French]

10. Omezzine $M$, Bouslama S, Nouri S, Moatamri $R$, Khochtali H. Congenital tumors of the oral cavity and cleft palate: presentation of 2 cases. Med Buccale Chir Buccale. 2011; 17:167-9. [Article in French]. 